\title{
MOLDE BARROCO Y SENSIBILIDAD DIECIOCHESCA: LA NOVELA LOS TRABAJOS DE NARCISO Y FILOMELA (1784), DE VICENTE MARTÍNEZ COLOMER
}

\section{Baroque Mold and Eighteenth Sensitivity: Vicente Martinez Colomer's Novel Los trabajos de Narciso y Filomela (1784)}

\author{
Javier MUÑOZ DE MORALES GALIANA \\ Universidad de Cádiz \\ Javier.munozdemorales@uca.es
}

Fecha de recepción: 14/06/2020

Fecha de aceptación definitiva: 18/03/2021

RESUMEN: Martínez Colomer compuso en 1784 su novela Los trabajos de Narciso y Filomela, aunque permaneció inédita hasta el año 2000. Por este motivo, apenas ha sido estudiada, y los trabajos existentes la vinculan sobre todo con el Persiles de Cervantes, obra de la que es imitación. No obstante, el presente trabajo se propone analizar esta novela atendiendo ya no solo a sus similitudes con el texto cervantino, sino a sus principales diferencias y peculiaridades. Demostramos, de este modo, que del Persiles únicamente toma lo más general, y a partir de ahí desarrolla una historia dotada de una sensibilidad típicamente dieciochesca.

Palabras clave: novela bizantina; Persiles; Cervantes; Ilustración; siglo XVIII.

ABSTRACT: Martínez Colomer composed in 1784 his novel Los trabajos de Narciso y Filomela, although it remained unpublished until 2000. For this reason, it has hardly been studied, and the existing works link it above all with Cervantes's Persiles, a text of which it is an imitation. However, the present work intends to analyze this novel taking into account not only its similarities with the Cervantes text, but also its main differences and peculiarities. In this way, we show that from 
Persiles only takes the most general, and from there develops a story endowed with a typically eighteenth-century sensibility.

Key words: byzantine novel; Persiles; Cervantes; Enlightenment; 18th Century.

\section{NOTICIA BIBLIOGRÁFICA}

Aunque compuesta en $1784^{1}$, la novela Los trabajos de Narciso y Filomela -a la que nos referiremos abreviadamente como «el Narciso»- permaneció inédita en su tiempo, y no se dio a conocer hasta que Antonio Cruz Casado la presentó al público en un artículo en el que incluía varios fragmentos de la obra ${ }^{2}$. Trece años después, ese mismo investigador publicó una edición crítica de esta ${ }^{3}$, que volvía a analizarla en un estudio preliminar, donde considera que El Narciso es un "caluroso homenaje de admiración a Cervantes», pero que también tiene interés por su carácter "prerromántico» ${ }^{4}$. La misma introducción, de hecho, incluye un apartado en el que explica la influencia de Cervantes en la novela, y también ofrece la explicación de algunos rasgos relacionados con el Romanticismo, sobre todo en lo relativo al estilo empleado por el autor.

Esta edición permitió que siete años más adelante se realizara un nuevo estudio sobre el Narciso, en el que se analizaba la obra prestando especial atención a la estructura y al argumento 5 . Desde entonces, la novela no ha vuelto a ser analizada ni estudiada, o al menos no nos consta, si bien es mencionada brevemente por Guillermo Carnero, quien ante todo la considera «una especie de ensayo de El Valdemaro y de alguna otra de sus narraciones [de Martínez Colomer] " $;$; Cruz

1. La composición de la obra queda situada en esa fecha por CRUZ CASADO, Antonio. "Introducción y notas». En MarTínez COlomer, Vicente. Los trabajos de Narciso y Filomela. 1. a edición. Córdoba: Diputación, 2000, p. 17.

2. Véase Cruz CASADO, Antonio. "El viaje como estructura narrativa: Los trabajos de Narciso y Filomela, de Vicente Martínez Colomer, una novela inédita (Presentación y textos)». Dicenda. Cuadernos de Filología Hispánica, 1987, 7, pp. 309-325.

3. Véase MarTínez COlOmer, Vicente. Los trabajos de Narciso y Filomela. Una novela cervantina del siglo XVIII. 1. ${ }^{a}$ edición de un texto inédito del XVIII, a cargo de Antonio Cruz Casado. Córdoba: Diputación, 2000. Todas las citas de la novela llevadas a cabo en este artículo provienen de esta misma edición.

4. Cruz Casado, 2000, op. cit., pp. 12-20.

5. Véase TeIJEIRO Fuentes, Miguel Ángel. "Los trabajos de Narciso y Filomela, una novela del XVIII en la órbita narrativa bizantina». En CAÑAs Murillo, Jesús y Roso Díaz, José (eds.). Aufklärung: estudios sobre la Ilustración española dedicados a Hans-Joachim Lope. 1. a edición. Extremadura: Universidad, 2007, pp. 123-134.

6. CARNERO, Guillermo. Estudios sobre narrativa y otros temas dieciochescos. 1. ${ }^{a}$ edición. Salamanca: Universidad de Salamanca, 2009, p. 152. A su vez, El Valdemaro también está considerado una imitación de Cervantes, como señala Cuevas Cervera, Francisco. El Cervantismo en el siglo XIX: Del Quijote de Ibarra (1780) al Quijote de Hartzenbusch (1863). 1. a edición. Oviedo: Universidad, 2015, p. 17. No son estos, no obstante, los únicos textos compuestos por Martínez Colomer con Cervantes 
Casado, de hecho, ya señaló cómo narraciones posteriores del autor, como La Narcisa, El petimetre pedante o El hallazgo de Alejandrina, retoman precisamente elementos ya presentes en esta novela ${ }^{7}$.

Hay, por tanto, estudios sobre la obra, pero quizá necesiten ser ampliados dada la importancia que consideramos tiene El Narciso. El artículo de 1987 es poco más que una presentación de esta. El estudio preliminar a su única edición, en el 2000, es muy completo, pero tiene un carácter demasiado general, sin profundizar demasiado en ninguno de sus rasgos; el de Tejeiro Fuentes resulta igualmente más descriptivo que valorativo. Pretendemos aquí, por tanto, entrar a valorar la importancia de esta obra para la historia de la literatura española, no sin antes referir brevemente su contenido.

\section{ARGUMENTO Y ESTRUCTURA}

A grandes rasgos, el argumento es un calco del de la obra cervantina Los trabajos de Persiles y Sigismunda, obra con la que mantiene paralelismos incluso en el título. El Persiles narraba las desventuras amorosas de dos príncipes nórdicos cuyos nombres figuran en el título, quienes son separados bruscamente y arrancados de su tierra natal, tras lo cual tienen que emprender una peregrinación por toda Europa hasta reencontrarse y contraer matrimonio una vez regresan a su país. A lo largo de su viaje, cambian de identidad y se hacen pasar por hermanos, con los nombres de Periandro y Auristela. Un argumento idéntico es el que tenemos en el Narciso, con la salvedad de que no son príncipes noruegos, sino cretenses. También aquí se mantiene la argucia de hacerse pasar por hermanos; en este caso, utilizando los sobrenombres de "Lisandro" ${ }^{8}$ y "Felisinda». Por lo demás, no hay significativas referencias argumentales con respecto a la obra cervantina, restando, claro está, las múltiples narraciones intercaladas habidas en una y otra novela. Pero, como bien advierte Bajtín, esta clase de narraciones se basan, sobre todo, en referir los sucesos de un "hiato extratemporal» que «se sitúa fuera del tiempo

como referente; también podemos destacar su colección de narraciones publicada con el cervantino título de Nueva colección de novelas ejemplares (1790). En el prólogo a una reedición que estas tuvieron en 1804, de hecho, afirma estar basándose en el «estilo fluido, sonoro y harmonioso que vemos en Cervantes»; Martínez Colomer, Vicente. Novelas morales. 2. ${ }^{a}$ edición [1. ${ }^{a}$ edición: 1790]. Valencia: Benito Monfort, 1804, s. p. A su vez, su novela El impio por vanidad (1795) guarda también cierto paralelismo con El Quijote en tanto que está protagonizada por un sujeto cuyo comportamiento queda condicionado por la lectura de un determinado tipo de textos, como se explica en MuÑOz DE MORALES GALIANA, Javier. "Los quijotes afrancesados: francofobia y reaccionarismo en la novela española de entre los siglos XVIII y XIX». En Fernández Moreno, Sergio; Mármol Ávila, Pedro y Pereira Melo, Yónatan (coords.). Aproximaciones al nacionalismo en las literaturas hispánicas. Madrid: Itsumustuan Editores, 2020, pp. 128-130.

7. Cruz Casado, op. cit., p. 21

8. Nombre, por cierto, bastante similar a Periandro, como bien advierte Cruz Casado, op. cit., p. 193. 
biográfico", ya que "no cambia nada en la vida de los héroes». Por tanto, las historias de Persiles y de Narciso son, en esencia, idénticas; únicamente cambian los matices de sus respectivos hiatos, que en ningún caso tienen mayor repercusión en sus vidas más allá de suponer un pronunciado paréntesis.

En lo que respecta a la estructura, el Narciso tampoco se aleja demasiado del modelo del Persiles. Al ser esta también una novela bizantina, podremos advertir una serie de rasgos estructurales muy marcados, como la complejidad y el enrevesamiento en la narración. Ya desde Heliodoro de Emesa ${ }^{10}$ el relato bizantino siempre estuvo repleto de distorsiones espaciotemporales que incrementaban el interés de la lectura; la presentación de acontecimientos en un orden no lineal, así como el empleo recurrente de analepsis y anagnórisis, son rasgos especialmente característicos de la narrativa bizantina que también están presentes en el Narciso; rasgos que, si bien sirven para aumentar la intriga y el misterio de la narración, pueden llegar a hacer de la misma algo bastante caótico y confuso. Por eso resulta especialmente meritorio el esfuerzo llevado a cabo por Teijeiro Fuentes en su citado artículo, donde logra exponer de forma bastante clara la estructura de la obra.

De manera muy resumida, el Narciso se estructura de la siguiente forma: comienza in medias res (pp. 49-51), con Felisinda -Filomela- a punto de ser violada en una choza alejada de la civilización. Allí es salvada de milagro por un hombre llamado Lisardo; poco después, se reúne con otros personajes, la señora Clara, sus hijos y el pastor Lenio. Estos acceden a acompañarla en una peregrinación que pretendía hacer hasta Zaragoza, y logran llevar a cabo una buena parte del trayecto, hasta llegar a la ciudad de Valencia (pp. 52-98). Allí se encuentran con Lisandro -Narciso-, a quien salvan de ser injustamente ejecutado, y les narra entonces los acontecimientos que lo llevaron hasta esa situación, analepsis que abarca varios capítulos (pp. 99-131). Tras juntarse los dos supuestos hermanos, prosigue el viaje hasta Zaragoza (pp. 132-150), en mitad del cual Felisinda relata parte de su pasado; concretamente, los acontecimientos que la llevaron a la situación en la que se encontraba al comienzo de la novela (pp. 151-152). Finalmente, llegan a Zaragoza, y allí Lisandro les propone a sus compañeros de viaje hacer uno nuevo hasta su patria, trayecto que tiene lugar inmediatamente después (pp. 153-184). Por último, se descubre la verdadera identidad de Lisandro y Felisinda, quienes se revelan como príncipes de Creta. Llegan a este país, se casan y la novela concluye con un final feliz (pp. 185-186). Todo este viaje es interrumpido constantemente, al igual que ocurría en el Persiles, por aventuras prescindibles e intercambiables - «extrabiográficas», en términos de Bajtín-, que poca relevancia tienen para el desenlace de la narración.

El argumento es poco más que un calco del Persiles y la estructura es la típica de cualquier novela bizantina, por lo que puede parecer más que justificado que

9. Bajtín, Mijail. Teoría y estética de la novela. 1. a edición. Madrid: Taurus, 1989, p. 242.

10. Creador del género de la novela bizantina con su novela Etiópicas. 
Teijeiro Fuentes afirme que las aportaciones originales de Martínez Colomer «no sean muchas ni excesivamente originales ${ }^{11}$. Sin embargo, si dejamos a un lado las similitudes de esta obra con la de Cervantes, lograremos advertir que, restando argumento y estructura, el Persiles y el Narciso son, en realidad, dos obras verdaderamente distintas. Por mucho que Martínez Colomer quisiese imitar a Cervantes, el autor del Narciso es hijo de una época completamente distinta al Siglo de Oro español. Los ideales de la Ilustración y el concepto dieciochesco de «sensibilidad" suponían el caldo de cultivo del contexto intelectual y literario de la España en el que el Narciso fue gestado, y ello tendría que implicar, necesariamente, una huella imborrable en la estética de la novela y en su cosmovisión.

Que Martínez Colomer tomase como modelo el Persiles y que decida establecer una estructura idéntica son hechos, por cierto, bastante significativos si tenemos en cuenta el contexto literario en el que surgió el Narciso. Pensemos en las novelas publicadas inmediatamente antes de 1784: nos encontramos con obras pedagógicas y satíricas, como el Fray Gerundio, Los enredos de un lugar o las Aventuras de Juan Luis ${ }^{12}$; todas ellas siguen una estructura narrativa bastante lineal, que apenas da lugar a la intriga ni al misterio. Es cierto que también empezaban a aparecer imitaciones cervantinas, pero solo del Quijote y no del Persiles; hablamos, concretamente, del Quijote de la Manchuela y de la Vida de Juan Mayorazgo, donde la estructura lineal se mantenía en favor de la intención pedagógica y satírica, como en las otras tres novelas mencionadas. Martínez Colomer, por tanto, escribe el Narciso en el contexto de un panorama novelístico en el que primaba más lo moral que el entretenimiento, y lo hace tomando un molde narrativo muy poco habitual para su época; molde, por cierto, que propicia mantener la atención del lector más que asegurar su instrucción moral.

No consideramos que las intenciones de este autor se limiten a imitar a Cervantes, sino que más bien toma el modelo del Persiles como punto de partida para llevar a cabo algo diferente y renovador. El propio autor, de hecho, lo declara así en la misma novela; defendiéndose de posibles acusaciones de plagio cervantino, alega que «si ha caído tal vez en este defecto, ha sido sin noticia de la voluntad, a causa de que como tiene tan leídos los escritos de Cervantes, como precisamente debe hacerlo cualquiera que pretenda imitar aquel estilo que más se le acomode» (p. 148). Los moldes cervantinos son los que más «se le acomodan» para su finalidad, pero no son su finalidad.

11. Op. cit., p. 124.

12. Para un catálogo de las novelas publicadas en aquellos años, véase BRown, Reginald F. $L a$ novela española 1700-1850. 1. a edición. Madrid: Dirección General de Archivos y Bibliotecas, 1953; si bien se debe tener en cuenta que dicho catálogo tiene numerosas carencias; novelas inéditas como el Narciso, por ejemplo, no son citadas. Para análisis de las respectivas novelas mencionadas, véase Álvarez BARrientos, Joaquín. La novela del siglo XVIII. 1. a edición. Madrid: Júcar, 1991. 


\section{DifERENCIAS CON RESPECTO AL PERSILES}

Si buscamos puntos en los que la obra se distancie de Cervantes, lo primero que salta a la vista, como bien advierte Cruz Casado, es el estilo, que no tiene mucho que ver con el del Persiles. Cruz Casado señala que la adjetivación es abundante y posee un "marcado carácter subjetivo", que entronca con la "tendencia romántica» ${ }^{13}$. Para ilustrar esto, pone varios ejemplos extraídos del comienzo de la narración: "espantoso ruido", "casa desierta», "horrorosos e incultos llantos», "altísimas peñas» (p. 2). Esto no solo es una peculiaridad de las primeras páginas, sino una constante que se mantiene en toda la obra: "delicioso jardín" (p. 58), "mortales desmayos» (p. 78), «enfurecidas olas» (p. 83), «finísimos diamantes» (p. 113), «cruelísimos dolores» (p. 135), «funestos accidentes» (p. 176). Adviértase el empleo recurrente de superlativos, que no solo denotan subjetividad, sino también un carácter más exaltado por parte del narrador. De igual forma, la adjetivación utilizada muchas veces lleva consigo el uso de la personificación -«incultos llantos» y "enfurecidas olas», por ejemplo-; la naturaleza es, así, contemplada como algo animado, vivo, dinámico, en consonancia con la sensibilidad de los personajes, que, como desarrollaremos, está en todo momento extremada.

Aparte de la adjetivación, Cruz Casado también destaca «la expresión sincopada, el empleo de los puntos suspensivos, los signos de admiración y otros rasgos que indican el desconcierto interior del personaje» ${ }^{14}$. Veámoslo de nuevo en distintos fragmentos: "Llegó el día tan deseado, ¡ay, señores! ¡Que no sé cómo pueda acordarme de él sin que el alma se despegue de estas carnes!, Llegó, digo, el día aplazado" (p. 69); "No, no. Funestas nuevas ocurren. Mi madre es muerta. Mi corazón me lo asegura. Él es fiel. Soltadme, que quiero ver con mis ojos lo que imagino» (p. 93); “¿Cuántas veces enlazará en mi cuello sus dulces brazos y, pegando sus labios con los míos, arrojará...? ¡Ay, hermano! ¡Qué imaginaciones tan alegres desmayan mis bríos y casi casi marchitan el verdor de mis esperanzas!» (p. 125). Todos estos fragmentos han sido tomados de boca de los propios personajes; tengamos en cuenta, a ese respecto, que gran parte de la acción es narrada por ellos mismos y no por el narrador omnisciente, lo cual permite un mayor despliegue de la subjetividad; como bien señala Bajtín, el género novelesco se caracteriza porque el habla de los héroes dispone "de autonomía semántico-literaria, de su propio horizonte, debido a ser un habla ajena en un lenguaje ajeno", motivo por el que "puede también refractar las intenciones del autor y, por lo tanto, puede representar en cierta medida el segundo lenguaje del autor ${ }^{15}$. Lo cierto es que ni siquiera cuando interviene el narrador omnisciente lo hace de forma objetiva, sino demostrando en todo momento cierta implicación emocional con los

13. CRuz CASADO, op. cit., p. 20.

14. Cruz Casado, op. cit., p. 20.

15. BAJTín, op. cit., p. 132. 
acontecimientos que está narrando: "Aguarda, bella Felisinda, aguarda; no te precipites; déjate llevar de la corriente de tus desgracias puesto que no puedes contrastarla» (p. 163); "Quéjese, pues, enhorabuena Felisinda, que no faltará quien se compadezca de su lástima y quien se enternezca al oír sus lastimosas razones» (p. 184). Vemos, así, cómo el narrador no se cuida de evitar exhortaciones conmocionadas a los personajes en el primer fragmento; en el segundo, a su vez, hay una reivindicación de la subjetividad y de la sensibilidad de sus protagonistas. Todo esto pone de relieve que no estamos ante un narrador estático y pasivo, sino sensible y susceptible de ser conmovido con su propia historia.

Tampoco tiene nada que ver esta omnisciencia con la habitual en la novela pedagógica, satírica o moral, inmediatamente anterior a la composición del Narciso. En ese tipo de narraciones era frecuente ver juicios morales por parte del autor. En el Fray Gerundio o en Los enredos de un lugar, por ejemplo, era muy difícil un narrador que empatizase con los personajes; por el contrario, vemos que ambos narradores se limitan a juzgarlos e incluso a ridiculizarlos. No pretenden despertar simpatía ni comprensión en el lector, sino utilizar a sus protagonistas como medio de enseñar lecciones morales. Vicente Martínez Colomer, en ese sentido, se distancia de este tipo de tendencias y ofrece en su Narciso un nuevo tipo de narrador, que también moraliza, pero que además se conmueve ante lo que él mismo está contando.

Este estilo, además, está muy lejos del retoricismo recargado tan propio del Barroco; el Persiles resulta una obra totalmente distinta si tenemos en cuenta el tono de ambos narradores. Martínez Colomer, como estamos viendo, tiende a un lenguaje sincopado, dinámico y sensible; en Cervantes, por el contrario, era muy abundante la concatenación de oraciones subordinadas en extensas sentencias que llegaban a ocupar párrafos notablemente extensos:

Pasó el rumor del caso, enterraron a Clodio, quedó Auristela vengada, como si en su generoso pecho albergara género de venganza alguna, así como albergaba en el de la Cenotia, que bebía, cual dicen, los vientos, imaginando cómo vengarse del cruel flechero, el cual de allí a dos días se sintió mal dispuesto y cayó en la cama con tanto descaecimiento que los médicos dijeron que se le acababa la vida, sin conocer de qué enfermedad ${ }^{16}$.

Advirtamos que Cervantes tiende a alargar sus oraciones, incluyendo en el proceso numerosas subordinadas; en el fragmento que acabamos de citar, de hecho, introduce algún excurso dentro de la misma oración. Esto dota al Persiles de una brillantez retórica y de un detallismo exacerbado; todo ello es totalmente incompatible con la pretensión de dinamismo habida en el Narciso, donde es más frecuente la sucesión de frases algo más cortas sin excursos de ningún tipo:

16. Cervantes, Miguel de. Los trabajos de Persiles y Sigismunda. $1 .^{a}$ edición [1. ${ }^{a}$ edición original: 1616]. Barcelona: Penguin Random House, 2016, p. 197. 
Así se lamentaba Felisinda entre aquellas escabrosas montañas. Parecíale que extenuada a las violencias de sus infortunios había de dejar entre ellas su vida sin remedio. Alzaba los ojos hacia las altas cumbres de los montes que la ceñían, pasaba la vista por los pendientes de ellos mismos, reparaba en aquellas enmarañadas malezas y espesos bosques, y volviendo sobre sí, le parecía estar allí solamente para ser infelice cebo de las fieras que los habitaban ${ }^{17}$.

Obsérvese que, al margen de los hechos narrados, el pathos cambia por completo en Cervantes y en Martínez Colomer; en el primero destaca, sobre todo, el deleite estético derivado de su complejidad léxica y sintáctica, mientras que en el segundo hay una pretensión de sentimentalismo violento por encima de todo lo demás. Con relación a este asunto, podemos advertir un interesante el comienzo del Persiles y del Narciso. Ambas narraciones comienzan in medias res, y ambas con una situación bastante violenta; la primera arranca hablando del cautiverio de varias personas en una horrible mazmorra y la segunda se inicia con un intento de violación. Sin embargo, Cruz Casado se da cuenta de lo muy destacable que supone el que la segunda no solo comience in medias res, sino también con las palabras de un personaje y no del narrador ${ }^{18}$. Veamos, primero, el inicio del Persiles:

Voces daba el bárbaro Corsicurvo a la estrecha boca de una profunda mazmorra, antes sepultura que prisión de muchos cuerpos vivos que en ella estaban sepultados. Y aunque su terrible y espantoso estruendo cerca y lejos se escuchaba, de nadie eran entendidas articuladamente las razones que pronunciaba sino de la miserable Cloelia, a quien sus desventuras en aquella profundidad tenían encerrada.

—Haz, joh Cloelia! — decía el bárbaro—, que así como está, ligadas las manos atrás, salga acá arriba, atado a esa cuerda que descuelgo, aquel mancebo que habrá dos días te entregamos; y mira bien si, entre las mujeres de la pasada presa, hay alguna que merezca nuestra compañía y gozar de la luz del claro cielo que nos cubre y del aire saludable que nos rodea ${ }^{19}$.

\section{Ahora veamos el del Narciso:}

- ¡No, bárbaro, no! Antes envainarás en mi propio pecho ese agudo cuchillo que empuñas, y primero derramará tu furor toda la sangre de mis venas, que yo me rinda al impetuoso ardor de tus malvados deseos. Las promesas, las dádivas, las amenazas, los castigos que importunamente me propones, no serán parte para que mi voluntad se sujete a la tuya tan díscola y depravada, que no sé cómo son tan sufridos los cielos que no han enviado ya un veloz rayo que te consuma. Apártate de mí, monstruo cruel, quítate de mi presencia: no presumas, joh loco! que porque me ves sola y sin fuerzas, has de lograr lo que procuras con tanta desvergüenza, que los cielos que están siempre atentos en defender a los que les sirven, me darán valor para que pueda desasirme de entre tus impuros brazos.

17. Martínez Colomer, Los trabajos de Narciso y Filomena, op. cit., p. 52.

18. Cruz Casado, op. cit., pp. 188-189.

19. Cervantes, op. cit., p. 49. 
Estas voces que, envueltas en un espantoso ruido, salían de una casa desierta y medio derribada, que se descubría en la metad ( $\mathrm{sic}$ ) de unos horrorosos e incultos llanos ceñidos de altísimas peñas, obligaron a que acudiese Lisardo que acaso acertó a pasar por aquellas cercanías ${ }^{20}$.

Ambos ejemplos narran, como ya hemos dicho, situaciones similares. En ambos hay un personaje gritando en una situación bastante violenta; sin embargo, el primero comienza con la narración de esos gritos, y luego dichos alaridos aparecen en estilo directo. Sin embargo, el segundo se inicia directamente con las voces en estilo directo, tal como decía Cruz Casado, y luego se introduce la narración; si tenemos en cuenta que, además, son las voces de una mujer que está intentándose defender de una violación ${ }^{21}$, el principio del Narciso nos resulta muchísimo más violento que el de su predecesor cervantino, violencia que queda acentuada por el estilo dinámico y agitado de Martínez Colomer. Por mucho que Cervantes relatase situaciones de violencia similar a las del Narciso, su exhaustividad retórica cohíbe una mayor implicación emocional por parte del lector, ya que los hechos nos son presentados con algo más de distancia.

Pensemos, por ejemplo, en otros dos pasajes bastante similares de ambas obras; a saber, los momentos en los que Periandro y Lisandro, respectivamente, narran casi todo lo que les ha acontecido hasta el momento presente. La narración de Periandro -Persiles- ${ }^{22}$ no tiene realmente nada que envidiar a la de Lisandro Narciso- (pp. 102-131) en cuanto a la violencia y agitación de los hechos narrados. Narciso se ve envuelto en todo tipo de lances truculentos; es apresado, por ejemplo, por musulmanes, y si logra escapar es con importantes dificultades, ya que una altiva mora le pretendía de amores (pp. 120-131)23. Persiles, de igual modo, cuenta que hubo un momento en el que se vio al mando de un escuadrón de piratas con los que tuvo todo tipo de aventuras a lo largo del $\operatorname{mar}^{24}$. Sin embargo, el tono de una y otra narración es completamente distinto, y la intensidad lírica de la de Narciso es mucho mayor que la de Persiles; veámoslo en fragmentos de ambas narraciones. Comencemos con la de Persiles; concretamente, con el momento en el que se pone al mando del escuadrón de piratas:

La baja fortuna jamás se enmendó con la ociosidad ni con la pereza; en los bajos ánimos encogidos nunca tuvo lugar la buena dicha; nosotros mismos nos fabricamos nuestra ventura y no hay alma que no sea capaz de levantarse a su asiento; los cobardes, aunque nazcan ricos, siempre son pobres, como los avaros mendigos. [...] $\mathrm{E}$ Ea, pues, amigos, juventud valerosa, poned los ojos en aquel navío que se lleva

20. Martínez Colomer, op. cit., p. 49.

21. Los atentados contra la castidad de las heroínas son un lugar común muy habitual en las novelas bizantinas, como señala BAjTín, op. cit., p. 240.

22. Cervantes, op. cit., pp. 198-258.

23. Esta clase de tentaciones a la castidad del héroe son motivos muy habituales y recurrentes en las novelas bizantinas, como señala BAjTíN, op. cit., p. 240.

24. Cervantes, op. cit., pp. 214-258. 
las caras prendas de vuestros parientes, encerrándonos en esotro, que en la ribera nos dejaron, casi, a lo que creo, por ordenación del cielo! Vamos tras él y hagámonos piratas, no codiciosos, como son los demás, sino justicieros, como lo seremos nosotros. A todos se nos entiende el arte de la marinería; bastimentos hallaremos en el navío con todo lo necesario a la navegación, porque sus contrarios no le despojaron más que de las mujeres; y si es grande el agravio que hemos recibido, grandísima es la ocasión que se nos ofrece. Sígame, pues, el que quisiere, que yo os suplico, y Carino y Solercio os lo ruegan, que bien sé que no me han de dejar en esta valerosa empresa.

Apenas hube acabado de decir estas razones, cuando se oyó un murmureo por todas las barcas, procedido de que unos con otros se aconsejaban de lo que harían y entre todos salió una voz que dijo: «Embárcate, generoso huésped, y sé nuestro capitán y nuestra guía, que todos te seguiremos ${ }^{25}$.

Cervantes no abandona su ampulosidad retórica ni en el momento en el que Persiles se dirige a sus piratas, ni al remitir la respuesta de estos últimos. Es una situación, desde luego, emocionante; sin embargo, las palabras escogidas puestas en boca de Persiles invitan más al deleite estético que a la exaltación de las emociones. Nada que ver con la narración de Narciso. El pasaje antes mencionado, en el que es pretendido de amores por una mujer de los musulmanes que lo capturaron, no tendría por qué ser especialmente más emocionante que la conversión de Persiles en pirata si nos ceñimos a valorar únicamente los acontecimientos de uno y otro pasaje. Sin embargo, la aventura de Narciso está escrita de tal forma que nos permite deducir cierta exaltación de los sentimientos:

Pasmada quedó Halima con tan no esperada resolución, y, ciega de su enojo, se levantó de improviso de donde estaba y se fue no sé a dónde, dejándome llena el alma de mil confusas cavilaciones. Todavía estaba luchando con ellas, cuando vi que, por la misma puerta por donde se había salido, entraba otra vez con dos turcos cargados, el uno con una gruesa y pesada cadena que llevaba sobre el hombro, y el otro de un cofre lleno de ricas joyas y preciosos vestidos; de todo lo cual, haciendo muestra a mis ojos, dijo:

-Veas cuál de estas dos suertes se te acomoda mejor: si tu voluntad se aviene con la mía que te he declarado, desde luego haré que mis esclavas te vistan los hábitos y joyas que encierra este cofre, para celebrar nuestros desposorios; si quieres mostrarte ingrato y perseveras tenaz en tu propósito, por el mismo estilo haré que te carguen esta pesada cadena, la cual no te quitarás de encima hasta que se te vaya el alma, y aun inventaré nuevos tormentos que sin quitarte la vida te la hagan más dura que la misma muerte ${ }^{26}$.

De estos dos textos, tal vez el de Cervantes sea más complejo desde el punto de vista retórico; no obstante, el segundo se sirve del estilo sincopado tan característico de Martínez Colomer, y ello le permite obtener un lirismo mucho más concentrado que

25. Cervantes, op. cit., pp. 214-215.

26. Martínez Colomer, op. cit., p. 123. 
el de Cervantes. Tengamos en cuenta también que, aunque ambas obras presentan estructuras y argumentos idénticos, la extensión del Persiles es mucho mayor. Los capítulos de las dos narraciones tienen una longitud más o menos similar, pero la de Cervantes cuenta con treinta y seis capítulos más que el Narciso; si tenemos en cuenta que, pese a ello, el argumento es idéntico, la acción de la de Martínez Colomer tiene que estar necesariamente mucho más concentrada. Esto implica que los acontecimientos se suceden mucho más rápido y con mayor intensidad, lo cual incrementa notoriamente la emotividad del relato. En el fragmento de Cervantes que hemos citado antes, tienen cabida todo tipo de digresiones e incluso exordios morales, como «los cobardes, aunque nazcan ricos, siempre son pobres». Tales digresiones imposibilitan que tenga lugar la tensión constante habida en la narración de Martínez Colomer. El fragmento que acabamos de citar es un buen ejemplo de ello: si en él se introdujese cualquier tipo de exordio, como los que introduce Cervantes, se perdería la tensión creada. Por el contrario, el narrador del Narciso es más ágil, dinámico y no se desvía del objeto narrado; bien es cierto que introduce varias narraciones dentro de la principal, pero los acontecimientos de estas son expuestos con presteza y vivacidad.

Al narrar, los personajes, de hecho, parecen reiterar el estilo de sus respectivos autores; tengamos en cuenta, como señala Bajtín, que «la novela griega [y bizantina] representa muy débilmente la palabra nueva de la conciencia plurilingüe „27. No obstante, ambas obras se distancian de lo habitual en el género, en tanto que, en este caso, las similitudes estilísticas de los personajes con los escritores son más verosímiles, dado que viven en un mundo cronológicamente muy cercano al de sus autores ${ }^{28}$. En el Persiles, esto puede verse, por ejemplo, en el capítulo décimo del tercer libro ${ }^{29}$, donde se hacen alusiones a la guerra contra los turcos, en la que participó el propio Cervantes, como algo contemporáneo a los personajes; se llega, incluso, a mencionar a algún individuo real, como el general Sancho de Leiva ${ }^{30}$. En cuanto al Narciso, resulta mucho más sencillo ubicarlo en un tiempo cronológico real, ya que hay cierto pasaje metaliterario bastante relevante al respecto, en el que los protagonistas se encuentran con un personaje que les habla de que su propia historia está siendo escrita (p. 146), algo similar a lo que ocurría con don Quijote al principio de la segunda parte. El autor, de esta manera, equipara cronológicamente el tiempo en el que los acontecimientos de

27. En todo momento Bajtín asimila las características de las llamadas "novelas griegas» a las novelas bizantinas, que considera "sus sucesoras directas más cercanas»; BAJTín, op. cit., p. 240; y BAJTín, op. cit., p. 432.

28. En la novela griega -y, por consiguiente, en la bizantina-, el universo desarrollado solía ser totalmente ajeno al "universo natal de donde proviene y desde donde observa el autor», como advierte BajTín, op. cit., p. 254. Que el Persiles rompa con esto supone un rasgo diferencial con el resto del género, que se mantendrá, de hecho, en el Narciso, en tanto que este último toma como referencia más el texto cervantino que lo habitual en las novelas bizantinas.

29. Cervantes, op. cit., pp. 327-334.

30. Cervantes, op. cit., p. 329. 
la novela tienen lugar con el mismo tiempo en el que el texto está siendo escrito. Hay, por ello, casi doscientos años de separación no ya solo entre sus autores y sus obras, sino también entre sus propios personajes. Resulta, por tanto, lógico y coherente que la sensibilidad de uno y otro personaje sean tan diferentes, pese a que sus actos sean tan parecidos y su carácter igualmente heroico.

\section{EL TEMA DEL SUICIDIO EN LA PERSPECTIVA EUROPEA}

El cambio de cosmovisión que implica el que hayan pasado casi dos siglos años es algo que no solo está presente en el protagonista de la obra, sino en toda la sociedad que su autor nos presenta. El otro personaje principal que aparece en el título de la novela, Filomela, es el equivalente a la Sigismunda de Cervantes, pero distará de esta más incluso que Narciso de Persiles. En el capítulo IX del primer libro, asistimos a una escena considerablemente definitoria del personaje, en la que Filomela hace gala de una intensa angustia existencial, e incluso llega a plantearse el suicidio, idea que más adelante es rechazada por su voluntad de perseverar (pp. 74-75). Para Cruz Casado, este pasaje es, fundamentalmente, algo típico de los libros de aventuras peregrinas; un manifiesto de rechazo al suicidio, como el que hay en las Etiópicas y en otras tantas novelas del género ${ }^{31}$. Teniendo en cuenta que este tema es algo habitual en la novela bizantina, su aparición en el Narciso no tendría por qué ser nada esencialmente novedoso, pero no consideramos que la sensibilidad con la que un autor trate el tema del suicidio en 1784 sea comparable a la de otros tiempos.

Personajes con intención de atentar contra su propia vida pueden encontrarse en cualquier período literario; sin embargo, a finales del XVIII el suicidio comienza a adquirir una dimensión especialmente relevante y un trato diferente y considerable por parte de muchísimos escritores. Tengamos en cuenta que la Ilustración había posibilitado un tratamiento de este asunto desde un punto de vista mucho más frío, racional y desprejuiciado; prueba de esto son las Cartas persas de Montesquieu, aparecidas ya en 1721. Su protagonista, Usbek, reflexiona y llega a la conclusión de que, desde un punto de vista totalmente racional, no hay nada de censurable en que un individuo tome la decisión de suicidarse ${ }^{32}$. La frialdad de la Ilustración tenía que posibilitar necesariamente el tratamiento de este asunto con una nueva sensibilidad por parte de los primeros románticos; así, en 1761 apareció la novela que constituyó las bases para el desarrollo del posterior Romanticismo, La nueva Eloísa ${ }^{33}$, y en ella el tema del suicidio tenía un relieve especial no

31. CRuz CASADO, op. cit., p. 194.

32. Montesquieu, Barón de. Cartas persas. $3 .^{a}$ edición $\left[1 .^{a}{ }^{a}\right.$ edición en castellano: 1819)]. Madrid: Tecnos, 2009, pp. 113-114.

33. VÁzQuez, Lydia. "Introducción». En Rousseau, Jean-Jacques. La nueva Eloísa. 1. a edición [1. ${ }^{a}$ edición original: 1813]. Madrid: Cátedra, 2013, pp. 9-110 (p. 96). 
solo por su importancia dentro de la obra, sino por la sensibilidad con la que es tratado. Saint-Preux, su protagonista, declara lo siguiente:

En cualquier lugar que me sitúe, ya sea en un cuerpo, ya sea en mi pueblo, es para quedarme mientras me encuentre bien, y para salir de ahí en cuanto me encuentre mal. Esa es la voz de la naturaleza y la voz de Dios. Hay que esperar la orden, convengo en ello; pero cuando muero naturalmente Dios no me ordena que deje la vida, me la quita; al hacérmela insoportable, me ordena que la deje. En el primer caso, me resisto con todas mis fuerzas, en el segundo tengo el mérito de obedecer ${ }^{34}$. Observemos que la postura de Rousseau con respecto al suicidio es el reflejo de una cosmovisión totalmente diferente a la que pudieran tener los autores de novelas bizantinas o cualquier otro escritor anterior a la Ilustración; ya no solo se habla del suicidio, sino que también se intenta legitimar moralmente. Incluso se llega a insinuar que ni siquiera el Dios del cristianismo debería prohibir un acto así, porque supondría un atentado contra la libertad del individuo. Poco después de La nueva Eloísa, ideas idénticas aparecerán en el Werther de Goethe (1774): «La naturaleza humana [...] tiene sus límites: puede soportar hasta cierto grado de alegría, las penas y sufrimientos, pero sucumbe en cuanto sobrepasa esa barrera. No se trata de si uno es fuerte o débil, sino de si puede soportar el grado de sufrimiento [...]. Y me parece igualmente absurdo tachar de cobarde a quien se quita la vida ${ }^{35}$. El suicida ya no es visto como un cobarde pecaminoso, sino como alguien que actúa de forma lógica, coherente y comprensible; ni siquiera es contemplado el acto de quitarse la vida como una cobardía.

Lo cierto es que, aunque la fecha de composición de estas dos obras es anterior a la del Narciso, resulta difícil plantear que hayan podido influir sobre Martínez Colomer. El Werther no se llegó a traducir del alemán hasta 1835, y no pudo influir entre los españoles contemporáneos ${ }^{36}$. Por otra parte, las obras de Rousseau estaban prohibidas en su totalidad por la Inquisición ${ }^{37}$, lo que no impidió que algunos intelectuales pudieran acceder a ellas; Cadalso, por ejemplo, se inspiró en parte en La nueva Eloísa para componer las Noches lúgubres ${ }^{38}$; en cuanto a Martínez Colomer, conocía sobradamente el francés y la literatura extranjera ${ }^{39}$, y muy probablemente hubiera leído parte de las obras de Rousseau, filósofo al que

34. Rousseau, Jean-Jacques. La nueva Eloísa. 1. ${ }^{a}$ edición [1. a edición en castellano: 1814]. Madrid: Cátedra, 2013, p. 619.

35. GoETHE, Johann Wolfgang von. Las desventuras del joven Werther. 21. a edición [1. a edición en castellano: 1835]. Madrid: Cátedra, 2012, p. 99.

36. GonZÁLEZ, Manuel José. «Introducción». En GoeTHE, Johann Wolfgang von. Las desventuras del joven Werther. 21. a edición [1. ${ }^{a}$ edición en castellano: 1835]. Madrid: Cátedra, 2012, pp. 11-50 (p. 43).

37. VÁZquEZ, op. cit., p. 73.

38. SEBOLD, Russell P. El rapto de la mente. Madrid: Prensa Española, 1970, p. 131.

39. Vicente Martínez Colomer dominaba el francés hasta el punto de poder llevar a cabo una traducción de Chateaubriand en 1813; véase CARNERO, op. cit., p. 142. 
referencia constantemente en su novela El impío por vanidad ${ }^{40}$. Queda igualmente abierta la posibilidad de que a esta nueva sensibilidad sobre el suicidio haya podido acceder nuestro autor de manera indirecta, gracias a autores españoles igualmente influenciados por Rousseau, como Cadalso. En cualquier caso, podemos aseverar que el interés de Martínez Colomer por el suicidio es una constante en su obra más allá de los tópicos de la novela bizantina, ya que, por ejemplo, $E l$ Valdemaro, su texto más famoso, se abre precisamente con una escena en la que el protagonista trata, aunque de manera fallida, de atentar contra su propia vida. De igual modo, encontramos un pasaje de un intento de suicidio en una obra tan ajena al género bizantino como lo es El impío por vanidad ${ }^{41}$.

Teniendo en cuenta, por tanto, el contexto literario y filosófico del momento, así como el interés particular del autor por este tema, todo exordio o reflexión en torno al suicidio que pudiera hacerse a fecha de 1784, y en una novela de Martínez Colomer, adquiriría otras connotaciones inexistentes en la anterior narrativa bizantina. Moralizar contra el homicidio motu proprio implicaba una marcada oposición dialéctica a todas las corrientes de pensamiento que plantearan tal acto como algo aceptable; no obstante, el autor en todo momento es consciente de toda la sensibilidad suicida que pueda haber en su tiempo, y precisamente parte de ahí para redirigir su crítica. Se muestra, así, comprensivo con los suicidas, pero también se apresura a ofrecerles otra alternativa preferible; esto podemos apreciarlo en el monólogo de Filomela, en el que ella se plantea atentar contra su propia vida, para más adelante rechazar por sí misma tal idea:

—iAy, infelice de mí! ¿Para qué quiero esta vida que tan amargamente sostengo? ¿De qué sirve alimentar mi tierno y delicado cuerpo, sino de hacer más duraderas las penas que padezco? ¿No sería más acertado dejarle consumir a los ardores de una ardiente sed y a los rigores de una hambre rabiosa? Sí. Pues está bien. Ejecútese mi determinación por más que parezca crueldad, comiéncese desde ahora... Pero no; advierte Felisinda que esta será muerte muy dilatada y con ella no lograrás tan presto el fin que a tu misma aspiras, que es acabar pronto con tu vida. Mejor será imaginar otro género de muerte que pueda acabar en un momento los infinitos de pena que te aguardan. Empuña un agudo cuchillo, abre con él tu pecho y hazle paso al alma para que se salga de ese cuerpo y se lleve la vida, o si no, prevén para el intento... Mas yo, ¿qué digo? ¿Estoy sin juicio? ¿Deliro? No, sí. ¡Justos cielos, cuán precipitadamente obra un entendimiento apasionado! ¡Cuán arrebatadamente discurre cuando se ve acosado de amotinadas pasiones! ¿Yo misma había de ser homicida de mí misma? ¡Qué delirio! No, cielos, no; alárguese mi vida todo el tiempo

40. En esa novela podemos apreciar, ante todo, una feroz crítica a la filosofía del ginebrino; véase MuÑoz DE Morales Galiana, Javier. «Un ejemplo de reaccionarismo católico contra la heterodoxia ilustrada en la España de finales del XVIII: la novela El impío por vanidad del padre Martínez Colomer». Cuadernos Dieciochistas, 2020, 21, pp. 487-518. Esto no impide que Rousseau haya podido influirle relativamente en su faceta literaria.

41. La importancia de tal escena en el conjunto de El impio por vanidad queda explicada en MuÑOZ DE MORAles Galiana, op. cit., pp. 509-510. 
que más os viniere en gusto, que con ella puede ser que enmiende, puede ser que se mejore hasta hoy infelice fortuna. Y cuando fuese yo tan desgraciada que ni se mejorara, ni se enmendara, viviré a los menos contenta de saber que mi voluntad no sola un punto de la vuestra ${ }^{42}$.

El rechazo al suicidio solo tiene lugar después de un impetuoso despliegue de pasiones funestas. Prestemos especial atención a las palabras marcadas en cursiva; se habla de "entendimiento apasionado", de "amotinadas pasiones"; hay, en definitiva, un superlativo sentimentalismo antes de que Filomela decida continuar con vida. Cruz Casado señala que las consideraciones morales que se desprenden del paisaje citado, relativas a que las pasiones deben contenerse y dominarse, podrían ser vistas como un discurso ilustrado ${ }^{43}$. El capítulo en el que tal pasaje tiene lugar, de hecho, comienza con un exordio moral acerca del control de las pasiones: "Cuando con impetuosa corriente se precipitan hacia nosotros las desgracias y los trabajos, no hay medio más poderoso para contrastarla que hacernos fuertes en una cristiana constancia y armarnos de una invencible paciencia» (p. 74). Sin embargo, adviértase que en todo momento es una Ilustración guiada siempre por la moral eclesiástica; no tiene mucho que ver con la actitud de Montesquieu o Rousseau, que abordaban el tema del suicidio de manera desprejuiciada. Una persona tan estrictamente católica como Martínez Colomer, fraile franciscano, podía ver en el suicidio más que cierta suerte de aberración moral; si se sirve de la razón y propone la contención de las pasiones es, en todo momento, para servir a los intereses de su religión.

Así pues, en esta novela los pensamientos suicidas solo asaltan a la protagonista en una ocasión y automáticamente son rechazados, pero este tema es una constante que se mantiene en toda la obra. La prueba de ello, aparte del pasaje citado, son los suicidas con los que los protagonistas se cruzan a lo largo de la novela. La narración ofrece un total de tres personajes que atentan contra su propia vida, y, aunque se trate de secundarios, consideramos que su presencia es especialmente significativa, ya que nos acerca a comprender el sentido último del texto.

El primero de ellos es Halima, la musulmana que se suicida tras pretender de amores a Narciso. En un principio, nuestro protagonista nos la presenta como una mujer buena y compasiva, "una hija del bey llamada Halima, moza y extremadamente bella, la cual, con corazón más cristiano de lo que prometía su profesión, me consolaba en mis desventuras muchas veces, y en alguna de ellas me mostraba ya con dádivas, ya con promesas, ya con palabras el amor que me tenía» (p. 120). Después, refiere que, tras la muerte de su padre, su carácter va variando paulatinamente, hasta el punto de empezar a llevar su afecto hacia Narciso hasta

42. Martínez Colomer, op. cit., pp. 74-75, la cursiva es nuestra.

43. Cruz Casado, op. cit., p. 20. 
lo obsesivo: «No sabía desviarse de mi lado ni un solo instante. En el paseo que de ordinario hacía en un hermoso jardín de la misma casa, mandaba que le acompañase, en la mesa me sentaba a su lado, en el resto del día no consentía que me apartase de su presencia; en fin, me trataba no como a un esclavo, sino como señor de su voluntad» (p. 121). Finalmente acaba pidiéndole matrimonio (pp. 121122), propuesta que es rechazada por Narciso rotundamente: "O ¿qué perderé si os pierdo a vos y a cuanto me prometéis? ¿Perderé acaso la vida? No sólo una, sino mil si tuviera sacrificara en este instante, a trueco de no rendir mi voluntad a vuestros deseos [...], que antes pisarán vuestros pies este desdichado cuerpo y antes arrancaréis de él el alma que encierra, que oigáis de mí otra cosa» (p. 123).

Obsérvese que en este fragmento Narciso actúa de manera heroica y arrojada; se siente no solo dispuesto a abandonar la vida, sino a precipitarse a la muerte con orgullo y entusiasmo. Antes de esta conversación, Halima se había mostrado enamorada y obsesiva; no obstante, el carácter apasionado de Narciso hará que ella se radicalice mucho en su actitud, hasta ser ella misma la que acabe suicidándose. Esta radicalización de su actitud empieza a verse en un fragmento, citado anteriormente, en el que intenta coaccionar a Narciso: «Si quieres mostrarte ingrato y perseveras tenaz en tu propósito, por el mismo estilo haré que te carguen esta pesada cadena, la cual no te quitarás de encima hasta que se te vaya el alma, y aun inventaré nuevos tormentos que sin quitarte la vida te la hagan más dura que la misma muerte» (p. 123). Obsérvese el paso de un enamoramiento algo obsesivo a una crueldad sin límites y a un egoísmo total. A Halima, en un principio, le preocupaba el bienestar de Narciso, y él veía en ella a una mujer llena de compasión; sin embargo, ella deja a un lado toda consideración en cuanto ve que no tiene posibilidades de enamorarlo si no es a la fuerza, y se convierte en una auténtica femme fatale: manipuladora, retorcida, cruel y terrible.

Con todo, es al ver que no puede subyugar de ninguna manera a su amado cuando decide volverse contra sí misma y arrancarse la vida: "Se dio una terrible palmada en la frente, metióse la mano en la faldriquera, sacó un agudo cuchillo, y diciendo solamente: ¡Ah, traidor!, se le hincó en el pecho y cayó en el suelo sin vida» (p. 129). Toda esta trama supone un espectáculo macabro mediante el cual el tema del suicidio adquiere una mayor relevancia en el conjunto de la obra; no solo es una cuestión que aparece mencionada para moralizar contra ella expresando el rechazo de los protagonistas, sino que también se ejemplifica en este personaje.

Además, al comenzar el tercer libro dan también con un hombre "con un cordel que tenía atado por la garganta» (p. 133); es decir, un suicida que había intentado quitarse la vida ahorcándose. Narciso, sin embargo, intenta salvarlo descolgándolo, intento que acaba siendo un fracaso porque muere igualmente (p. 137); lo cierto es que antes de morir tiene tiempo de contarle a los protagonistas los motivos que le han arrastrado al suicidio, lo que tiene gran interés para lo que aquí nos ocupa. Halima era un personaje mostrado desde la perspectiva de Narciso, y en ningún momento se le daba la oportunidad de expresar demasiado su subjetividad; no obstante, caso distinto es el de este nuevo suicida -Eduardo-, 
que puede explicar que el motivo de su suicidio es una cuestión de honra; él y su mujer pertenecían a los estamentos más altos de la sociedad, pero su hija pretendía casarse con un verdugo, lo cual suponía una vergüenza para la familia (p. 135). La obsesión de Eduardo con el tema lo arrastra hasta una actitud excesivamente cruel y desconsiderada para con su hija: «iAh, hija cruel! ¡Y cuán mejor te fuera o no haber nacido, o haberte ocultado entre las sombras de la muerte antes de llegar a tan infeliz extremo!» (p. 136). Sin embargo, y al igual que en el caso de Halima, la agresividad de Eduardo contra la situación que está viviendo lo arrastra a volverse contra sí mismo como forma de negar y rechazar la realidad: «Por no vivir con tanta infamia, me ausenté de mi patria y me fui por esos caminos, acompañado sólo de mis melancólicas y confusas imaginaciones, las cuales batiendo de continuo en mi alma me redujeron al infeliz extremo que habéis visto» (p. 137).

La historia de Eduardo es, ante todo, una tragedia que quizá nos evocaría a las de Calderón, puesto que la honra adquiere condición fundamental. Lo cierto es que la sensibilidad con la que Martínez Colomer trata este tema supone un reflejo de los cambios sociales que encontramos desde el siglo XVII. Eduardo es un personaje que vive en un mundo ya anticuado, en el que la honra y el prestigio familiar tienen importancia por encima de todo. Sus planteamientos retrógrados chocan con los de un mundo nuevo en el que la movilidad social cada vez es más acusada, por lo que no resulta especialmente extraño la posibilidad de un matrimonio de un verdugo con una mujer de clase alta. Sin embargo, no logra comprender los cambios de su época; anclado en una mentalidad antigua, se siente desbordado por la nueva cosmovisión, y por ello nota que ya no tiene nada que hacer en un mundo que no cuenta con él ni con su filosofía de vida. Estos motivos acaban arrastrándolo al homicidio motu proprio como forma de dar la espalda a un mundo que le es extraño y ajeno.

Curiosamente, el último suicida aparecido en la obra es, precisamente, la hija de Eduardo: Isabela. Con ella se encuentran casi al final de la novela, y les habla del mucho dolor que le supusieron sus amores con Rosendo, el hijo del verdugo. Ella es consciente de que una relación en semejantes circunstancias sociales no puede prosperar, pero su carácter apasionado le impide rechazar sus sentimientos: "Bien sabía yo cuánto daño causaba en mi alma tan loca pasión, pero no podía desasirme de ella, porque estaban ya muy hondas y retorcidas sus raíces» (p. 172, la cursiva es nuestra). De nuevo aquí aparece el irracionalismo y la exaltación de las pasiones; Isabela es consciente de lo destructivos que son sus amores, pero no por ello logra evitar sus sentimientos. De esta forma, acaba viéndose en una situación muy similar a la de muchísimos héroes románticos; intenta sublevarse contra las leyes de la sociedad en la que vive y actuar por su propia cuenta, pero eso únicamente la arrastra hasta su perdición, a la desgracia que les trae a sus padres; la madre había muerto de pena y Eduardo, como hemos visto, se había suicidado al no poder aceptar sus ilícitos amores. En cuanto Narciso se da cuenta de quién es Isabela, se apresura a explicarle lo acontecido a sus progenitores; y 
ella, al advertir las consecuencias de sus pasiones funestas, también acaba optando por el suicidio como mejor opción, al igual que su padre:

— ¿Conque muertos mis padres — replicó ella—, y viva yo que fui la causa de la muerte de ellos? No es justo.

Y sin hablar más palabra se arrojó al mar de improviso, dejando a todos pasmados y atónitos con tan no esperada desesperación. Asomáronse presurosos al borde del navío, pero de ningún modo pudieron socorrerla, porque ya las aguas se la habían llevado a los abismos ${ }^{44}$.

La historia de Isabela nos permite comprender la de Eduardo desde el punto de vista totalmente opuesto. Su padre era un personaje de mentalidad conservadora y anticuada, a quien la realidad que le ha tocado vivir le resulta demasiado ajena como para sentirse cómodo en ella; Isabela, por el contrario, ve frustrados sus deseos precisamente por el conservadurismo imperante en su cultura, que aún no ha desaparecido del todo, y que todavía continúa latente en la figura de sus padres. En ambos casos, la solución que encuentran es la misma: el suicidio.

La historia de Halima tenía una capital importancia en la obra, porque era una parte fundamental del pasado de Narciso, y servía para ilustrar las penalidades por las que el héroe había tenido que pasar. Las historias de Eduardo e Isabela, sin embargo, pueden no parecer tan importantes, porque no afectan directamente a los protagonistas. Lo cierto es que tienen una funcionalidad fundamental en la novela, esto es, prolongar la presencia de dos de los temas principales, el suicidio y la exaltación de las pasiones. Narciso logra escapar de la furia apasionada de Halima y ya se encuentra a salvo; con todo, sus encuentros con Eduardo e Isabela le suponen un perfecto recordatorio de cómo es la realidad en la que vive. Aunque Halima ya no pueda hacerle daño, el mundo sigue repleto de personas desequilibradas de todo tipo, de apasionados exaltados que no dudan en arrebatarse la vida cuando es necesario. Eduardo e Isabela, por tanto, contribuyen a configurar el espacio caótico en el que la novela se desarrolla; Narciso y Filomela se ven obligados a vivir en mundo en el que reina el desequilibrio emocional y el apasionamiento egoísta, y, para poder lograr llevar a buen puerto sus amores, tendrán que mostrar estar por encima del ambiente social en el que se desarrollan sus aventuras.

\section{EL AMBIENTE PERVERSO Y LA VIRTUD MORAL}

Lozano-Renieblas advertía que en el Persiles el protagonista «no pertenece a un mundo portador de valores que le permitan adquirir una identidad ${ }^{45}$. Ello se

44. MarTínez COlOMER, op. cit., pp. 173-174.

45. Lozano Renieblas, Isabel. "Introducción». En Cervantes, Miguel de. Los trabajos de Persiles y Sigismunda. 1. ${ }^{a}$ edición [1. ${ }^{a}$ edición original: 1616]. Barcelona: Penguin Random House, 2016, pp. 
debe a lo que vimos que mencionaba Bajtín en relación a las novelas griegas y bizantinas en general, esto es, el carácter extrabiográfico de la mayor parte de los acontecimientos narrados. En el Narciso, sus protagonistas no viven en un mundo carente de valores, sino en uno repleto de concepciones morales extrañas y egoístas que les son completamente opuestas. Y el desequilibrio del mundo en el que viven no solo se manifiesta en la historia de los tres suicidas que acabamos de ver; antes de la aparición de estos, ya hay otros personajes de pasiones egoístas y exaltadas que nos permiten comprender las características del entorno narrativo por el que avanzan nuestros protagonistas.

Ya en el comienzo de la novela, veíamos al personaje de Idomeneo, un violador egoísta y obsceno sin ningún pudor al atentar contra la integridad de Filomela. No mucho después de esta primera escena, los protagonistas se encuentran con Leonisa, una mujer guerrera, de carácter bravo y atrevido, que se subleva contra su condición femenina al encaminar su vida a la carrera militar, "ocupada sólo en los rigores de Marte, sin dar acogida a las blanduras de Venus» (p. 64). Sin embargo, ella acaba viéndose presa de unos amores trágicos, y su reacción al respecto resulta no poco llamativa:

Avistéle bien desimaginado de lo que le había de suceder, y con semblante airado y ademán soberbio, le dije: "-Alza esos infames ojos, oh malvado, y mira si me conoces. ¿Soy yo Leonisa? ¿Soy yo aquella misma a quien tú diste la mano de esposo? Pues ¿por qué traidor tan pronto te has olvidado de tus obligaciones, enredándote entre la inútil yedra de esa mozuela, que más parece muñeca que dama? [...] Di, traidor, di, ¿qué disculpa das de las culpas que cometiste? Pero no, no te fatigues en buscar satisfacciones que darme, que para mí ninguna será de provecho. Sólo esta me satisface». Y sin hablar más palabra empuñé una daga que traía para el intento, se la envainé en el cuerpo y le arranqué el alma, pero no quise arrancar la daga, por no tener conmigo instrumento manchado con su vil sangre ${ }^{46}$.

Leonisa se rebela contra el hombre que la ha hecho sufrir y le da muerte; tenemos, así, otro personaje de acciones exaltadas y pasiones extremas, aunque en este caso no sea una suicida; caso idéntico es el del borracho con el que se encuentran en el segundo capítulo del segundo libro, un hombre nihilista y descreído que no se rige por valor moral alguno, que reivindica su hedonismo desenfrenado: "¿Hay por ventura sanidad que iguale, pero qué digo iguale, ni aun le llegue a la suela del zapato de la enfermedad que nos embiste, cuando envasamos las tripas de buen vino? [...] Todo es paz, todo quietud, todo júbilo y todo gloria» (p. 85). Apréciese aquí una actitud materialista y descreída, que antepone el placer terrenal al goce espiritual; actitud que lo lleva a proferir las más tremebundas blasfemias: "Por nuestras lenguas y por nuestras bocas andan todos los demonios y todos los diablos que hay en el infierno y fuera de él. Ni hay blasfemia que no

\footnotetext{
9-34 (p. 18).

46. Martínez Colomer, op. cit., pp. 65-66.
} 
digamos, ni disparate que no profiramos, ni obscenas y escandalosas palabras que no saquemos a plaza» (p. 86).

A priori, esta actitud parece más propia de cualquier personaje de Espronceda que de un autor ilustrado del siglo XVIII, llegando no solo a la blasfemia, sino también al satanismo en la reivindicación del infierno y de los demonios. No obstante, Cruz Casado considera que el encuentro con el borracho es uno de los pasajes en los que se hace evidente la intención pedagógica e ilustrada de la novela, principalmente por el rechazo que muestran los protagonistas ante la actitud de este personaje ${ }^{47}$. Sin embargo, es innegable, tras todos los ejemplos que acabamos de ver, que, precisamente para moralizar, Martínez Colomer ha creado un espacio narrativo completamente inmoral, en el que el apasionamiento más violento está por todas partes. Empezando por el intento de violación del comienzo de la novela, la inmoralidad se prolonga mediante los personajes de Leonisa, el borracho y los tres suicidas. Vemos, así, que todos estos personajes secundarios que acabamos de detallar no suponen casos aislados en sí mismos, sino que contribuyen a una finalidad fundamental para la novela, esto es, la creación de un entorno ya no solo hostil, sino perverso y degenerado, en el que los protagonistas tendrán que mantenerse virtuosos para lograr llevar a buen puerto sus amores. El espacio, por tanto, juega un papel fundamental en otro de los rasgos de la novela bizantina que establece Bajtín, esto es, la puesta a prueba de los héroes, cuya virtud e identidad es puesta en cuestión constantemente en las aventuras que atraviesan, a las que deben mantenerse impasibles ${ }^{48}$.

La perversidad del entorno es algo que, de hecho, no solo se refleja en los desequilibrios de los personajes con los que se encuentran; además de eso, las descripciones del espacio suelen estar envueltas en connotaciones de peligro y maldad. A ello contribuye, precisamente, el estilo de la novela, del que ya hemos hablado bastante; recordemos que la novela se inicia en «una casa desierta y medio derribada, que se descubría en la metad ( sic) de unos horrorosos e incultos llanos ceñidos de altísimas peñas» (p. 49); a su vez, en el pasaje en el que Narciso es pretendido de amores por Halima, este acaba siendo encerrado «en una oscura y profunda mazmorra, en la cual estuvimos encerrados cuatro días, sin darnos de comer más que algunos granos arremojados» (p. 120). Espacios narrativos así contribuyen a que Cruz Casado llegue a vincular el Narciso con la novela de terror y la novela gótica ${ }^{49}$; quizá sea muy precipitado afirmar que esta obra pueda ser incluida en tales géneros, pero los elementos góticos aquí presentes son indudables ${ }^{50}$.

47. Cruz CaSAdo, op. cit., p. 20.

48. BAJTÍN, op. cit., p. 259.

49. Cruz Casado, op. cit., p. 190.

50. Lo cierto es que, pese a todo, el Narciso no aparece en el catálogo de novelas españolas con motivos góticos elaborado por López SANTOS, Miriam. La novela gótica en España (1788-1833). 1. ${ }^{\mathrm{a}}$ edición. Vigo: Academia del Hispanismo, 2010, pp. 281-282. 
Se podría decir, sin embargo, que en la novela de Cervantes también hay detalles así: recordemos, por ejemplo, que al comienzo de la novela se habla de «una profunda mazmorra, antes sepultura que prisión de muchos cuerpos vivos que en ella estaban sepultados ${ }^{51}$. Sin embargo, el estilo de Cervantes hemos visto que es en todo momento diferente, y poco cercano al propio del XVIII. De igual modo, en el Persiles también hay personajes bastante desequilibrados, pero son presentados con una sensibilidad que no nos lleva a empatizar con ellos tanto como con los del Narciso. Así, en el capítulo diecisiete del tercer libro, Cervantes se refiere a una de las antagonistas, Ruperta, como una mujer "agraviada y airada, y con tanto deseo de vengarse de su contrario que, aunque sabía que ya era muerto, dilataba su cólera por todos sus descendientes, sin querer dejar, si pudiera, vivo ninguno dellos, que la cólera de la mujer no tiene límite ${ }^{52}$. Esta forma de referirse al personaje poco tiene que ver con los pasajes que hemos visto, en los que Martínez Colomer da rienda suelta a la subjetividad de Leonisa y Halima; con estos dos últimos, de hecho, logramos empatizar más que con los personajes perversos aparecidos en el Persiles. Cervantes, en el fragmento que acabamos de citar, aprovecha para moralizar al referirse a esa mujer; Martínez Colomer también introduce alusiones didácticas, pero después de haber presentado al personaje y logrado que simpaticemos mínimamente con él.

En definitiva, los personajes desequilibrados y los espacios góticos, ambos elementos bastante recurrentes en el Narciso, posibilitan la configuración de un entorno perverso y retorcido que se aleja bastante del mundo del Persiles. Y a la perfidia de este entorno, los protagonistas se deben anteponer mediante el amor y la virtud. Ya hemos visto, a este respecto, el pasaje en el que Filomela rechaza el suicidio; al final de la obra, además, el autor vuelve a elogiar la capacidad de los personajes para anteponerse al entorno en el que han vivido sus aventuras: "Quedaron solemnemente desposados con el aplauso general de ambos reinos, habiendo subido de punto la nobleza y energía de su carácter con las lecciones que aprendieron en la escuela de las desgracias, que es en la que se forman los mayores hombres» (p. 186, la cursiva es nuestra). Observemos lo resaltado en cursiva: la obra concluye haciendo alusión a la formación de los protagonistas; vemos, de nuevo, afán de didactismo moral.

Insistimos, no obstante, en que la virtud moral para un fraile católico como Martínez Colomer, que era un escritor bastante tradicionalista, se diferenciaba notoriamente de otros ilustrados; hablar del triunfo de la razón sobre las pasiones quizá resulte demasiado simplista. Pensemos, por ejemplo, en la actitud indómita de Filomela al comienzo de la novela o en el ímpetu suicida de Narciso en el pasaje en el que es apresado por Halima: tales muestras de apasionamiento no son

51. Cervantes, op. cit., p. 49.

52. Cervantes, op. cit., pp. 368-369. 
tenidas por algo reprochable, sino por actitudes dignas de elogio, que contribuyen a construir esa "nobleza y energía de su carácter».

Obsérvese, de hecho, la alusión a su carácter «enérgico»; esto nada tiene que ver con, por ejemplo, novelas didácticas en la línea del Eusebio de Montengón, publicada dos años después de la composición del Narciso. En la novela de Montengón, el protagonista es instruido para aprender a controlar las pasiones, para convertirse en un ser paciente y racional por encima de todo. No ocurre así, ni mucho menos, con Narciso y Filomela; bien es cierto que ambos aprenden a estar por encima de algunas pasiones, pero no de todas. El trasfondo moral de la obra implica que la virtud no se logra con la represión de todas las pasiones, sino con la negación de unas y la exaltación de otras. Concretamente, el ímpetu metafísico y apasionado con el que se vive la religión cristiana es contemplado aquí como una suerte de emotividad digna de ser exaltada cuanto haga falta. Los héroes de esta obra son un hombre y una mujer de acción, respectivamente, y destacan moralmente no por un carácter racional, sino "enérgico", motivado en buena medida por el amor que sienten el uno hacia el otro. Y no hablamos ya de un amor caótico y descontrolado, como ocurría en el Werther o en las Noches lúgubres, sino de un amor casto y conyugal, asociado irrevocablemente al compromiso y al matrimonio cristiano. Es ese amor, precisamente, el que les proporciona la energía, la pasión y el coraje suficientes para anteponerse a los «trabajos" ${ }^{33}$ a los que se ven obligados a enfrentarse a lo largo de la novela; es lo que le permite tanto a Filomela enfrentarse a su violador, como a Narciso desafiar a su captora.

Consideramos, por tanto, que el tono tradicionalista y católico es el que impera en el Narciso, a pesar de lo ilustrado y en ocasiones gracias a lo ilustrado; la sensibilidad dieciochesca, en cualquier caso, es aquí muy tenida en cuenta. Pensemos, si no, en los tres temas principales aquí tratados: el suicidio, la exaltación de las pasiones y el amor. El suicidio es presentado como una tentación en la que no se debe caer, pero a pesar de ello el autor ofrece un mundo repleto de suicidas con los que podemos empatizar y a los que podemos comprender. La exaltación de las pasiones es vista como algo censurable solo en algunas ocasiones, en aquellas relativas a la desesperación previa al suicidio o las conductas perniciosas para con el prójimo; finalmente, en lo que respecta a las pasiones consideradas «nobles» por el autor, ya no se censura, sino que se alaba la exaltación de estas. Y es precisamente el amor la más noble de estas pasiones, que supone, además, el tema central de la obra; es un amor casto y conyugal, pero no por ello menos intenso, puesto que acaba convirtiéndose en la principal fuerza motora de la actitud arrojada y exaltada de los protagonistas.

53. Cruz Casado entiende que la aparición de la palabra "trabajos" tanto en el título del Persiles como en el del Narciso hace referencia, fundamentalmente, a las penalidades que tienen que atravesar los amantes a lo largo de ambas narraciones; véase Cruz CaSAdo, op. cit., p. 187. 


\section{BiBLiografía}

Álvarez BarRientos, Joaquín. La novela del siglo XVIII. 1. a edición. Madrid: Júcar, 1991.

BajTín, Mijail. Teoría y estética de la novela. 1. ${ }^{a}$ edición. Madrid: Taurus, 1989.

Brown, Reginald F. La novela española 1700-1850. 1. a edición. Madrid: Dirección General de Archivos y Bibliotecas, 1953.

CARnero, Guillermo. «Introducción». En Martínez Colomer, Vicente. El Valdemaro. $1 .^{a}$ edición [1. ${ }^{a}$ edición original: 1792]. Alicante: Instituto de estudios Juan Gil Albert, 1985, pp. 9-47.

CERvantes, Miguel de. Los trabajos de Persiles y Sigismunda. $1 .{ }^{a}$ edición $\left[1 .{ }^{a}\right.$ edición original: 1616]. Barcelona: Penguin Random House, 2016.

CRUZ CASADO, Antonio. «El viaje como estructura narrativa: Los trabajos de Narciso y Filomela, de Vicente Martínez Colomer, una novela inédita (Presentación y textos)». Dicenda. Cuadernos de Filología Hispánica, 1987, 7, pp. 309-325. URL: https://revistas.ucm.es/ index.php/DICE/article/view/DICE8888110309A

CRUz CASADO, Antonio. "Introducción y notas». En MARTínez Colomer, Vicente. Los trabajos de Narciso y Filomela. 1. ${ }^{\text {e }}$ edición. Córdoba: Diputación, 2000.

Cuevas Cervera, Francisco. El Cervantismo en el siglo XIX: Del Quijote de Ibarra (1780) al Quijote de Hartzenbusch (1863). 1. ${ }^{a}$ edición. Oviedo: Universidad, 2015.

GoETHE, Johann Wolfgang von. Las desventuras del joven Werther. 21. ${ }^{a}$ edición [1. ${ }^{a}$ edición en castellano: 1835]. Madrid: Cátedra, 2012.

GonZÁlez, Manuel José. "Introducción». En Goethe, Johann Wolfgang von. Las desventuras del joven Werther. 21. ${ }^{a}$ edición [1. ${ }^{a}$ edición en castellano: 1835]. Madrid: Cátedra, 2012, pp. 11-50.

López SANTOs, Miriam. La novela gótica en España (1788-1833). 1. ${ }^{a}$ edición. Vigo: Academia del Hispanismo, 2010.

LOZANO Renieblas, Isabel. «Introducción». En Cervantes, Miguel de. Los trabajos de Persiles y Sigismunda. 1. ${ }^{a}$ edición [1. ${ }^{a}$ edición original: 1616]. Barcelona: Penguin Random House, 2016, pp. 9-34.

Martínez Colomer, Vicente. Novelas morales. $2 .^{a}$ edición $\left[1 .{ }^{a}\right.$ edición: 1790]. Valencia: Benito Monfort, 1804.

MarTínez Colomer, Vicente. Los trabajos de Narciso y Filomela. Una novela cervantina del siglo XVIII. 1. ${ }^{a}$ edición de un texto inédito del XVIII, a cargo de Antonio Cruz Casado. Córdoba: Diputación, 2000.

Montesquieu, Barón de. Cartas persas. 3. ${ }^{a}$ edición [1. ${ }^{a}$ edición en castellano: 1819]. Madrid: Tecnos, 2009, pp. 113-114.

MuÑOZ DE MORALES Galiana, Javier. «Los quijotes afrancesados: francofobia y reaccionarismo en la novela española de entre los siglos XVIII y XIX". En FERnÁNDEZ Moreno, Sergio; Mármol Ávila, Pedro y Pereira Melo, Yónatan (coords.). Aproximaciones al nacionalismo en las literaturas hispánicas. Madrid: Itsumustuan Editores, 2020, pp. $128-130$.

MuÑoz DE Morales Galiana, Javier. «Un ejemplo de reaccionarismo católico contra la heterodoxia ilustrada en la España de finales del XVIII: la novela El impio por vanidad del padre Martínez Colomer». Cuadernos Dieciochistas, 2020, 21, pp. 487-518. URL: https://revistas.usal.es/index.php/1576-7914/article/view/cuadieci202021487518

RousseAu, Jean-Jacques. La nueva Eloísa. $1 .^{\text {a }}$ edición [1. ${ }^{a}$ edición en castellano: 1814]. Madrid: Cátedra, 2013. 
SEBOLD, Russell P. El rapto de la mente. Madrid: Prensa Española, 1970

TeIJeIRo FuenTES, Miguel Ángel. "Los trabajos de Narciso y Filomela, una novela del XVIII en la órbita narrativa bizantina». En CAÑas Murillo, Jesús y Roso Díaz, José (eds.). Aufklärung: estudios sobre la Ilustración española dedicados a Hans-Joachim Lope. 1. ${ }^{\mathrm{a}}$ edición. Extremadura: Universidad, 2007, pp. 123-134.

VÁzQuez, Lydia. «Introducción». En Rousseau, Jean-Jacques. La nueva Eloísa. 1. a edición [1. ${ }^{a}$ edición original: 1813]. Madrid: Cátedra, 2013, pp. 9-110. 